\title{
Language and culture conflict in the conversation amongst Malaysian children
}

\begin{abstract}
Language and culture conflict exists when the rise of the opposition in comprehension of language and culture between two community groups. The conflict in language and culture that undergo by the people in Malaysia with relation to the contemporary lifestyle and also the living environment and culture. With this matter, each civilised society has and complies to the rules inhering their language and culture. Culture includes arts, belief, custom, institution, creation, language, technology and value. The need of language and culture was to ascertain society in order to behave according to what the community wants and follow the language and culture patterns which has been prescribed. With the understanding of the language and culture in a community, conflict could be avoided. Hence, this paper will discuss the language and culture conflict among the Malaysians. Second, to describe the language and culture aspects that can be obtained from the conflict raised among the Malaysian community. The study sample comprises of 30 pupils studying in primary school from rural and urban area. Data were gathered using recording, interviewing, and distributing questionnaire. Data will be analysed by using socio-pragmatic approach. The outcome of the research also indicated that aspects of context and cognition have also played an important role in Malaysian's communication. Some youngsters provide the information that is inherent in their cognition to the relevant context. The contexts inherent functioned to provide meanings to the utterances concerned.
\end{abstract}

Keyword: Language and Culture Conflict 